\title{
LABOR MOBILITY AND FISCAL COORDINATION
}

\author{
Assaf Razin \\ Chi-Wa Yuen
}

Working Paper 5433

\section{NATIONAL BUREAU OF ECONOMIC RESEARCH \\ 1050 Massachusetts Avenue \\ Cambridge, MA 02138 \\ January 1996}

This paper is part of NBER's research program in International Finance and Macroeconomics. Any opinions expressed are those of the authors and not those of the National Bureau of Economic Research.

(C) 1996 by Assaf Razin and Chi-Wa Yuen. All rights reserved. Short sections of text, not to exceed two paragraphs, may be quoted without explicit permission provided that full credit, including $\odot$ notice, is given to the source. 


\title{
LABOR MOBILITY AND FISCAL COORDINATION
}

\begin{abstract}
Using a human capital based growth model, we show the essential role of labor mobility and cross-country tax harmonization in equalizing income levels of countries that start off from different initial income positions. Knowledge spillovers cum labor mobility are the driving forces behind the income level equalization process. In the absence of tax harmonization within an economic union, equality in income levels is not achievable. Coordination of educational subsidies necessary for the internalization of knowledge spillovers may or may not be necessary. These considerations constitute the basis for our efficient growth agenda for an economic union such as the EU.
\end{abstract}

Assaf Razin

Research Department, IS 12-906

International Monetary Fund

700 19th Street, NW

Washington, DC 20431

and NBER
Chi-Wa Yuen

School of Economics and Finance

University of Hong Kong

Pokfulam Road

HONG KONG 


\title{
LABOR MOBILITY AND FISCAL COORDINATION:
}

\author{
by
}

\author{
Assaf Razin and Chi-Wa Yuen
}

December 1995

\section{Introduction}

Europe has reached almost complete integration in capital markets through the 1992 'single market' initiative. Risk-adjusted and currency-adjusted rates of return on capital are, to a large extent, equalized across countries/regions in Europe. However, the European labor markets are still very much segmented across regions and countries. Compared with the US as a benchmark, a key difference for the European single market lies in the degree of labor mobility and the speed of adjustment of the labor markets to regional disturbances.

Comparing the United States and the European Union, an argument can be made that the latter is characterized by relatively low degree of labor mobility. A proxy for labor mobility is discussed by Eichengreen (1990). He summarized unemployment differentials within the EU (previously EC) and the US. Figure 1 portrays the dispersion of unemployment rates for nine regions in the US and countries in the EU. All three dispersion measures he considers (i.e., absolute differences, standard deviations, and coefficients of variation) are higher in the EU than in the US. This is consistent with the hypothesis that interregional labor mobility is greater in the US than in the EU. Another important difference between the US and the EU is the change in the average level of the unemployment dispersion measures over time. While the absolute difference in the US regional unemployment rates rises from less than $2 \%$ in the early 60 s to 
more than $5 \%$ in the $80 \mathrm{~s}$, that for Europe rises from $4 \%$ to $10 \%$. It thus appears that the labor markets are also slower to adjust to regional disturbances in Europe than in the US. This is another evidence for greater labor mobility in the US than in the EU.

A new evidence on the absence of labor mobility in parts of Europe is brought out by Blanchard and Jimeno (1995), who look at the asymmetry between macroeconomic performance of Portugal and Spain in terms of their unemployment rates. ${ }^{1}$

OECD (1990) provides yet another proxy. Internal migration measured by persons who changed country of residence in percentage of total population, in 1986 , was about $1.3 \%, 1.1 \%$, $0.5 \%$, and $1.1 \%$ for members of the EU: France, Germany, Italy, and the UK respectively. Evidently, these are overestimates for the cross-EU-members migration. In the same year, internal migration in the US was $3.0 \%$.

One should distinguish between labor mobility on the one hand and migration on the other. By labor mobility, we mean a situation where workers retain their source country residence while working in another country. By migration, we mean a permanent change of country residence. In the former, wage differentials are the single most important driving force; while, in the latter, other non-wage characteristics (e.g., language and culture) play also an important role. One important factor that makes labor mobility within Europe relatively low is the safety net system (e.g., pension/social security system and unemployment benefits) which is country-specific and not easily portable across countries whereas, in the US, it is mostly

\footnotetext{
${ }^{1}$ We hasten to add, though, that such pattern in the unemployment dispersion figures can, in principle, be a consequence of the possibly different unemployment benefits (especially citizen-based) across Europe as well. Whether and by how much it reflects the degree of labor mobility or the size of unemployment benefits or both is an issue that can only be resolve empirically.
} 
federal (e.g., unemployment benefits and social security) or privatized (e.g., pension). ${ }^{2}$

Per capita income levels are significantly different between North and South Europe. We surmise that labor mobility may act as a channel through which convergence in income levels can be achieved faster than through mobility in capital and goods and services alone. It thus remains as a challenge for the European Union to design policies to facilitate the movement of labor across different regions.

A necessary (but not sufficient) condition for income convergence is convergence in income growth rates. As is well-known in the growth literature, there is a fundamental positive relation between the rate of growth of per capita income and the real rate of interest, which is in turn equated to the marginal product of capital. (See, e.g., Rebelo (1992).) The diversity of income growth rates across countries can thus be related to the diversity of marginal productivities of capital across countries. It has been argued that international differentials in marginal products of capital and labor across countries are explainable not only by differences in capital-labor ratios, but also by the presence of knowledge spillovers which are confined within regional/national borders. Based on naive capital-labor ratio calculations, for example,

\footnotetext{
${ }^{2}$ We are grateful to Chris Pissarides for clarifying to us the need to be specific about the kind of barriers to labor mobility we have in mind and the important role played by non-wage compensating differentials in determining labor mobility. OECD (1990, p.67) emphasizes that two key potential barriers to mobility are housing regulations and the nonportability of private pensions. They say that "... [d]istortion in housing markets creating a disincentive for mobility can arise from three types of government intervention:

- rents in public housing are often below market prices, generating queues for access ...

- controls on private sector rents often create a situation where either properties for new rentals are unavailable, or rents for longstanding tenants are much below market levels.

- house purchase and sale is taxed at high rates (in some countries over $10 \%$ of the sale price), tax costs may create a significant discentive to moving...

Occupational (employer) pensions may constitute a second disincentive to job mobility. Universal coverage under occupational pensions exist in only a small number of countries, notably Sweden. In other countries, such as the $U K$ and the US, around 50\% of the workforce is covered, while in most other European countries the proportion is much smaller. Occupational pensions may be of the "defined contribution" from benefits in which there is an individual account for each participant. This type of pension is generally incentive-neutral. However, occupational pension can also take a "defined benefit" form ..." , which is not portable and therefore creates disincentive for mobility.
} 
one can find out from data in Summers and Heston (1988) significantly higher real wage in North Europe than in South Europe. This is plausibly a consequence of the marked difference in skills or human capital between North and South European workers. Correcting for these differences, one may still find that the wage per unit effective labor in North Europe is still much higher than that in its South counterpart. This could be a direct consequence of the low degree of labor mobility within Europe. With identical technologies, when labor has a higher marginal product in the North, capital must have a higher marginal product in the South. We may then have a puzzle: why capital from the North does not flow into the South so as to equate the marginal products of capital (especially since capital is freely mobile within Europe). To some extent, the puzzle can be resolved by resorting to such factors as socio-political unrest and technological risk. Based on the new developments in growth theory, as Lucas (1990) suggests, the following resolution of the puzzle can be provided. That is, there is no essential difference in the marginal products of capital between the North and the South. Instead, there is only a productivity difference that is generated by an external effect from human capital. The idea is that investment in human capital does not only augment the effective labor supply of the worker who made the investment, but also contributes to the productivity of all other workers and capital alike. The interaction between such knowledge spillovers and labor mobility can have important implications for the speed of growth in each European country and the European Union at large and the convergence in income levels across North and South Europe. This, indeed, will be an important feature of our analytical framework in this paper.

Another characteristic of the integration of European markets is the implementation and process of tax harmonization across member countries. Relative to other economic entities (such 
as the states within the US, where income tax rates are more or less the same across states), however, the tax burden among the European countries is unevenly distributed. For example, estimates of effective average tax rates by Mendoza, Razin, and Tesar (1994) for 1988 show that the labor income tax rates in France, Germany, Italy, and the UK are $47.2 \%, 41.2 \%, 40.9 \%$, $26.8 \%$ respectively, while capital income tax rates for these countries are $25.6 \%, 24.2 \%$, $27.5 \%$, and $59.0 \%$. As research results from the recent endogenous growth literature reveal, taxes are an important determinant of growth and asymmetric income tax rates can potentially generate huge diversity in income growth rates across countries. (See, e.g., Rebelo (1991).) Hence, this uneven tax burden could be viewed as an obstacle to a full integration of Europe.

Countering the effects of the limited degree of labor mobility and the uneven tax burden on the differences in income levels across EU countries, income transfers across the EU states have been carried out primarily through the EU Structural Funds program, which aims at transferring resources to regions whose incomes are persistently below the EC average. The question is how effective such income redistribution policy is in closing the interstate income gaps. In particular, in what magnitude and for how long will such transfers have to be made in order to close the gaps?

The three related issues of labor mobility, uneven tax burden, and growth are the subject matter of the present paper. It is organized in the following manner. In Section II, we introduce a stylised endogenous growth framework. Section III analyzes cross-country income convergence in the absence of taxes, highlighting the importance of the interaction among capital mobility, labor mobilty, and knowledge spillovers. In Section IV, we embed income taxes into the model to analyze tax harmonization. Section $\mathrm{V}$ examines growth policies necessary to 
internalize intra- and inter-country knowledge spillovers in the presence of labor mobility. Section VI concludes.

\section{The Model}

To set the stage for our analysis, we present a stylised endogenous growth model as in Frenkel, Razin, and Yuen (1996). We assume a dynastic economy with $N_{t}$ identical individuals in each period $(t=0,1,2, \ldots)$. The growth process in this economy is driven by the accumulation of physical capital, human capital, and population. ${ }^{3}$ The representative agent cares about his own consumption $c_{t}$ and the contemporary dynastic population $N_{t}$. To keep the analysis tractable, preferences of the dynastic head of the representative family are assumed to be isoelastic:

$$
\sum_{t=0}^{\infty} \beta^{t} N_{t}^{\xi}\left(\frac{C_{t}^{1-\sigma}}{1-\sigma}\right)
$$

where $\beta$ is the subjective discount factor, $\xi$ an altruism parameter, and $\sigma$ the inverse of the

${ }^{3}$ Given the close connection between population growth and economic growth in the development process and as a broadening of the definition of the problem of development, we shall devote equal emphasis to accounting for the observed diversity in the growth of (per capita and aggregate) income as well as population. When population growth is determined exogenously, taxes can only affect income growth through the growth engine (say, human capital), with indistinguishable effects on the growth of per capita income and aggregate income. Endogenizing population growth will introduce a new channel through which taxes can affect per capita income growth and aggregate income growth differently. Besides, as shown in Frenkel, Razin, and Yuen (1996), Chapter 15, a world steady state equilibrium (under either capital or labor mobility, or both) will not exist, in general, in the presence of tax differences. Introducing an additional source of growth which, similar to human capital, involves time-consuming activities, viz., endogenous population growth, will help restore the possibility of a steady state. 
intertemporal elasticity of substitution in consumption. ${ }^{5}$

In each period $t$, there are $N_{t}$ members in the representative household (given $N_{0}$ at $t=0$ ). Each household member is endowed with one unit of non-leisure time and possesses $h_{t}$ of human capital and $\mathrm{K}_{\mathrm{t}}$ of physical capital carried over from period $\mathrm{t}-1$ (given $\mathrm{h}_{0}$ and $\mathrm{K}_{0}$ at $t=0$ ) in each period $t$. He/she can split the unit time among three time-consuming activities-working ( $\mathrm{n}_{t}$ for number of worked hours), learning in schools (e for education), and child-rearing $\left(v_{t}\right.$ for vitality). As we shall see later on, child-rearing, which is the driving force for population growth, will be an essential element in our analysis of the tax-growth relations. $\mathrm{He} / \mathrm{she}$ also has to decide how much to save in the form of physical capital $\left(\mathrm{K}_{\mathrm{t}+1}-\left(1-\delta_{\mathrm{K}}\right) \mathrm{K}_{\mathrm{t}}\right)$ and bonds $\left(\mathrm{B}_{\mathrm{t}+1}-\left(1+\mathrm{r}_{\mathrm{t}}\right) \mathrm{B}_{\mathrm{t}}\right)$, where $\delta_{\mathrm{k}}$ is the rate of depreciation of physical capital and $\mathrm{r}_{\mathrm{t}}$ the bond rate of interest. Newly acquired effective labor $\left(\mathrm{H}_{t}=n_{t} N_{t} h_{t}\right)$ and physical capital $\left(K_{t}\right)$ accumulated from the previous period are supplied to the labor and capital markets in each period at the prevailing competitive wage $\left(w_{t}\right)$ and rental $\left(r_{k t}\right)$ rates. Implicit in the specification of effective labor $\left(H_{t}\right)$ as the product of worked hours $\left(n_{t}\right)$, number of workers $\left(N_{t}\right)$, and their human capital level $\left(h_{t}\right)$ is the assumption of perfect substitutability among these three objects in the supply of labor.

The dynamics of the two growth engines are determined as follows. Following Uzawa (1965), Razin (1972), and Lucas (1988), we model the contribution of the schooling activity to human capital growth as:

${ }^{5}$ As long as $\xi>0$, altruism is reflected not only in preference for 'quantity', but also 'quality' (as measured by their living standard in terms of consumption per capita), of children-since, with positive $\xi$, there is weight given to quantity, but the weight on the consumption term is magnified as well. Observe that if $\xi>1-\sigma$, then there will be a relative bias in preference towards quantity; whereas if $\xi<1-\sigma$, the bias will be in the opposite direction. 


$$
h_{t+1}=B\left(e_{t}^{\gamma}\right) h_{t}+\left(1-\delta_{h}\right) h_{t} \text {, }
$$

where $\mathrm{B}$ is the knowledge efficiency coefficient, $\gamma$ the productivity parameter, and $\delta_{\mathrm{h}}$ the rate of depreciation of human capital. Similar to Razin and Ben Zion (1974) and Becker and Barro (1988), the child-rearing activity gives rise to population growth:

$$
N_{t+1}=D\left(v_{t}^{\alpha}\right) N_{t}+\left(1-\delta_{N}\right) N_{t},
$$

where $\mathrm{D}$ and $\alpha$ are the fertility efficiency coefficient and productivity parameter, and $\delta_{\mathrm{N}}$ the mortality rate respectively. ${ }^{6}$

The family budget constraint is given by: $N_{t} c_{t}+K_{t+1}-\left(1-\delta_{k}\right) K_{t}-B_{t+1}+$ $\left(1+r_{t}\right) B_{t} \leq w_{t} H_{t}+r_{k t} K_{t}$. The optimization problem facing the dynastic head is to choose $\left\{c_{t}, e_{t}, n_{t}, K_{t+1}, N_{t+1}, h_{t+1}, B_{t+1}\right\}_{t=0}^{\infty}$ to maximize (1) subject to (2), (3), and the budget constraint, given $\left\{w_{t}, r_{t}\right\}_{t}^{\infty}=0$.

Final output is produced by competitive firms using physical capital $\left(\mathrm{K}_{\mathrm{t}}\right)$ and total effective labor $\left(\mathrm{H}_{\mathrm{t}}\right)$ via a Cobb-Douglas technology with a knowledge spillover effect (captured by the upper tail of skill distribution, i.e, the level of human capital of the smartest guy in the population, $\left.\overline{\mathrm{h}}_{\mathrm{t}}\right): \mathrm{Y}_{\mathrm{t}}=\mathrm{AK}_{\mathrm{t}}^{1-\alpha_{\mathrm{H}}}{ }_{\mathrm{t}}^{\alpha_{\mathrm{h}}} \underset{\mathrm{t}}{\epsilon}$, where $\mathrm{A}$ is the production coefficient, $\alpha$ the output share of labor, and $\epsilon$ the externality parameter. The external effect captures the possibility that, through investment in human capital, the individual not only enhances his earning ability, but (if $s /$ he turns out to be the most knowledgeable/skillful guy in the population) also generates

\footnotetext{
${ }^{6}$ One can think of $N_{t+1} / N_{t}$ as one plus the number of children per family (when the number of parents is normalized to unity). The child-rearing cost (v) is increasing with the number of children. $\mathrm{Dv}^{\alpha}$ is therefore the inverse function of this cost-quantity relation. $v$ will be assumed fixed and given when we consider the case of exogenous population growth.
} 
knowledge spillovers by contributing to the aggregate level of productivity. ${ }^{7}$

Since investment decisions in physical and human capital are made at the household level, the firm's problem is static in nature, viz., to choose the amount of capital $\left(\mathrm{K}_{\mathrm{t}}^{\mathrm{d}}\right)$ and effective labor $\left(\mathrm{H}_{\mathrm{t}}^{\mathrm{d}}\right)$ in each period $\mathrm{t}$ to maximize profit $\mathrm{Y}_{\mathrm{t}}-\mathrm{w}_{\mathrm{t}} \mathrm{H}_{\mathrm{t}}^{\mathrm{d}}-\mathrm{r}_{\mathrm{kt}} \mathrm{K}_{\mathrm{t}}^{\mathrm{d}}$, given $\mathrm{w}_{\mathrm{t}}$ and $\mathrm{r}_{\mathrm{kt}}$.

Goods produced are either consumed by the private sector $\left(\mathrm{N}_{\mathrm{t}} \mathrm{c}_{\mathrm{t}}\right)$ or invested in the form of physical capital $\left(\mathrm{K}_{\mathrm{t}+1}\right)$. Hence, we can write the economy-wide resource constraint as:

$$
N_{t} C_{t}+K_{t+1}-\left(1-\delta_{k}\right) K_{t}=Y_{t}=A K_{t}^{1-\alpha} H_{t}^{\alpha} \bar{h}_{t}^{\epsilon}
$$

The equilibrium wage rates $\left(w_{t}\right)$ and interest rates $\left(r_{k t}\right.$ and $\left.r_{t}\right)$ are determined in the labor, capital, and bond markets under market clearing: $n_{t} N_{t} h_{t}=H_{t}^{d}, K_{t}=K_{t}^{d}$, and $B_{t}=B_{t}^{d}$.

\section{Convergence in the Absence of Taxes}

Let us now address the so-called convergence issue. Distinction has to be made between growth rate convergence and level convergence in income. By growth rate convergence, we mean a world equilibrium in which countries starting from different initial positions follow in the long run the same rates of growth of output. By level convergence, we mean a world equilibrium in which countries starting from different initial positions reach in the long run the same levels of income. These two concepts of convergence will be examined in two different

\footnotetext{
${ }^{7}$ This external effect is similar, but not exactly identical, to the Lucas (1988)-type externality, which is captured by the economy-wide average level of human capital). Despite their differences, they both inply that, without barriers, capital and labor will move in the same direction, contrary to the prediction of the standard theory (in the absence of the external effect). Atkeson and Bayoumi (1993) provide evidence from regions of the US which is consistent with this framework. They compare measures of interregional capital flows (as indicated by differences between regional income and product levels) and interregional population movements. Their data show that, by and large, population flows mirror the flows of capital. It appears, therefore, that labor and capital have been flowing to the same areas for the past two decades rather than moving in opposite directions as the standard theory predicts. See their Tables 2 and 3.
} 
contexts: a world without mobility of factors of production across national boundaries and an integrated world economy in which factors of production are internationally mobile. In what follows, although we refer to labor mobility only, capital mobility is also assumed in cases where labor mobility is allowed-given our opening statement that Europe has achieved almost complete integration in capital markets. As we shall see, unlike traditional trade theory, these two kinds of factor mobility are not perfect substitutes as driving forces for income level convergence.

\section{III.1 Absence of Labor Mobility}

Under our specification of technology, the intertemporal condition is given by $\left(\mathrm{N}_{\mathrm{t}+1} / \mathrm{N}_{\mathrm{t}}\right)^{1-\xi_{(}}\left(\mathrm{c}_{\mathrm{t}+1} / \mathrm{c}_{\mathrm{t}}\right)^{\sigma}=\beta\left[(1-\alpha) \mathrm{A}\left(\mathrm{K}_{\mathrm{t}+1} / \mathrm{H}_{\mathrm{t}+1}\right)^{-\alpha} \overline{\mathrm{h}}_{\mathrm{t}+1}^{\epsilon}+\left(1-\delta_{\mathrm{k}}\right)\right]$. Along the steady state growth path, the constancy of $N_{t+1} / N_{t}, c_{t+1} / c_{t}$ and $n_{t+1}$ requires that $\left(\mathrm{K}_{\mathrm{t}+1} / \mathrm{N}_{\mathrm{t}+1} \mathrm{~h}_{\mathrm{t}+1}\right)^{-\alpha} \overline{\mathrm{h}}_{\mathrm{t}+1}^{\epsilon}$ be constant. This implies that $\mathrm{K}_{\mathrm{t}}$ must grow at the same rate as $N_{t+1} h \xi_{+1}$, where $\zeta=1+\epsilon / \alpha(>1)$ and we have used the equilibrium condition: $\bar{h}_{t}=h_{t}$ in our representative agent economy. Defining $\hat{K}_{t}$ and $\hat{H}_{t}$ as the detrended values of $K_{t}$ and $H_{t}$ (i.e., $\mathrm{K}_{\mathrm{t}} /\left(1+\mathrm{g}_{\mathrm{K}}\right)^{t}$ and $\mathrm{H}_{\mathrm{t}} /\left[\left(1+\mathrm{g}_{\mathrm{N}}\right)\left(1+\mathrm{g}_{\mathrm{h}}\right)\right]^{t}$ ) respectively and rearranging terms, we can write

$$
\hat{K}_{t}=\left[\frac{\beta(1-\alpha) A}{\left(1+g_{N}\right)^{1-\xi}\left(1+g_{c}\right)^{\alpha}-\beta\left(1-\delta_{k}\right)}\right]^{1 / \alpha} n \hat{H}_{t}^{K},
$$

where $1+g_{c}$ can be shown to equal $\left.\left(1+g_{h}\right)\right\}$. This equation is represented by the convex curve between $\hat{\mathrm{K}}_{\mathrm{t}}$ and $\hat{\mathrm{H}}_{\mathrm{t}}$ in Figure 2, which portrays the steady state relation between the detrended stocks of physical and human capital. Countries starting from different initial positions on the $\hat{\mathrm{H}}_{\mathrm{t}} \hat{\mathrm{K}}_{\mathrm{t}}$ plane will, in general, converge to different long run positions on the convex curve, 
implying different levels of detrended income in the long run. This is because convexity of the curve implies that the capitals ratio $\left(\hat{\mathrm{K}}_{\mathrm{t}} / \hat{\mathrm{H}}_{\mathrm{t}}\right)$ will increase with $\hat{\mathrm{H}}_{\mathrm{t}}$, and thus be different across countries with different $\hat{\mathrm{H}}_{\mathrm{t}}$. Note that, in the absence of knowledge spillovers $(\epsilon=0$ or $\zeta=$ 1), this curve will become a ray from the origin with constant slope $\{\beta(1-\alpha) A$ $\left./\left[\left(1+\mathrm{g}_{\mathrm{N}}\right)^{1-\xi_{(}}\left(1+\mathrm{g}_{\mathrm{c}}\right)^{\sigma}-\beta\left(1-\delta_{\mathrm{k}}\right)\right]\right\}^{1 / \alpha} \mathrm{n}$, implying convergence in long run detrended income levels across countries. The external effect is therefore a fundamental force behind income diversity.

\section{III.2 Presence of Capital Mobility}

Under free capital mobility, capital will move from the low MPK (marginal product of capital) country to the high MPK country. These cross border capital flows will equalize the MPKs in all countries. From the intertemporal marginal conditions, we obtain the fundamental steady state growth equation (a la Rebelo (1992)):

$$
\left(\frac{1+g_{y}}{1+g_{y}^{*}}\right)^{(\xi-1)+\sigma \zeta}=\frac{1+r_{k}-\delta_{k}}{1+r_{k}^{*}-\delta_{k}} .
$$

Equalization of $r_{k}$ and $r_{k}^{*}$ thus implies equalization of $g_{y}$ and $g_{y}^{*}$ (unless $\xi=1-\sigma \zeta$ ). In other words, capital mobility will bring about growth rate convergence in the long run, with no implications for level convergence.

\section{III.3 Presence of Labor Mobility}

Under free labor mobility, workers will move from low-wage countries to high-wage countries. Over time, such cross-border labor flows will equalize the wage rates prevailing in 
all countries. In the long run, an empirically relevant steady state world equilibrium will involve positive net labor flows from some countries to some other countries. ${ }^{8}$

Let us now try to understand how labor mobility may affect the convergence in long term growth rates across countries. In the world steady state equilibrium, the non-zero net labor flows of each country must be growing at the same rate as its total income. But since the labor inflow of one country is equal to the labor outflow of another country, the steady state (balanced growth) restriction forces the total income growth rates to be uniform across countries in the long run.

This total growth rate equalization result is not specific to labor mobility. Similar arguments show that capital mobility will yield the same result. Even so, we cannot therefore conclude that labor mobility and capital mobility are perfect substitutes (as they indeed are in the exogenous growth context)? In particular, labor mobility (in the presence of knowledge spillovers) can bring about level convergence, something that is not achievable under capital mobility. ${ }^{9}$

Consider again two isolated economies, the home country and the rest of the world

\footnotetext{
${ }^{8}$ Without further restrictions, two other situations are possible in the long-run: (a) all workers in the world reside in one single country; and (b) no cross-border labor flows (i.e., back to autarky). Both are unrealistic cases. Some plausible assumptions can be made to eliminate them even as theoretical possibilities. Case (a) will not occur if the marginal product of labor becomes infinitely high when the labor remaining in any labor-exporting country gets sufficiently small (i.e., the Inada conditions can rule out this corner solution). Case (b) will not occur as long as the countries are heterogeneous in some fundamentals. (If they were homogeneous in all respects, labor flows would not have taken place in the first place.) Since we want to investigate the role of taxes on growth, we shall assume in Section 3 below that asymmetry in labor income tax rates is the factor that first induced cross-border labor flows. Suppose further that these countries were travelling along their steady state growth paths initially. Should these taxes remain different, the driving force that initiated labor flows to begin with will be reactivated if the countries revert to their longrun autarky growth paths. As such, (b) can also be ruled out. The only empirically interesting case that remains is the one that involves non-zero flows. In that case, we should expect the direction of labor flows to be from low after-tax wage countries to high after-tax wage countries.
}

${ }^{9}$ That level convergence is not, in general, achievable under capital mobility is shown in Frenkel, Razin, and Yuen (1996), Chapter 15. 
(denoted by superscript ${ }^{{ }^{*}}$ '), that have identical preferences and technologies, but possibly different endowments of physical and human capital. Even without capital mobility, interest rates will be equalized across these two economies in the long run (i.e., along their autarky balanced growth paths) as their steady state physical capital-human capital ratios converge to the same value. In the presence of the external effect associated with human capital in the production process, wage rates in these two economies will differ as long as the skill levels of their workers are different. With labor mobility, workers will naturally move from low wage (human-capital-poor) countries (say, the home country) to high wage (human-capital-rich) countries (say, the rest of the world). Since labor will flow from the home country to the rest of the world, the fraction of native effective labor working in the rest of world, $\eta^{*}$, equals 1 and the corresponding fraction in the home country, $\eta$, lies between 0 and 1 . The effective work force in the home country is $\eta_{t} n_{t} N_{t} h_{t}$ and that in the rest of the world is $n_{t}^{*} N_{t}^{*} h_{t}^{*}+\left(1-\eta_{t}\right) n_{t} N_{t} h_{t}$.

Suppose that while some workers from the home country choose to work in the rest of the world, they continue to accumulate their human capital in their own country. Although the extent of knowledge spillovers may be limited by national boundaries, labor mobility provides an indirect channel of raising the productivity of labor in the labor-exporting country. This is because, as a result of labor mobility and wage equalization, guest workers in the foreign country will immediately enjoy an upward shift in their wage profile and so will 'those left behind' working in the home country. This will provide the incentive for the home population to increase their rate of human capital accumulation (while that in the foreign population remains unchanged). In this sense, workers from the home country enjoy the fruits of the knowledge externality (i.e., equal pay) while working with the more skilled workers in the rest of the 
world, and these will get transmitted to their countrymen. It is in this sense that these workers can be viewed as 'messengers' of technological progress. Over time, this knowledge transmission will lead to equalization in the levels of human capital and income per capita in the whole world. ${ }^{10}$

In more formal terms, the above level-equalizing argument can be stated as a proposition.

Proposition: Along the steady state growth path with nonzero labor flows and $\epsilon>0, g_{h}=g_{h}^{*}$ and $\hat{h}=\hat{h}^{*}$.

[Proof: see Appendix 1.]

To sum up, we have shown in the closed economy context that the spillovers associated with human capital formation are essential in order to generate diversity in long run income levels. In its absence, (detrended) income levels of countries similar in preferences and technology will converge. On the other hand, a combination of human capital externality and labor mobility is shown to be essential to restore level convergence. Thus, knowledge spillovers are both a source of divergence (in the absence of labor mobility) and a source of convergence (in the presence of labor mobility).

\section{Tax Harmonization and Convergence}

Suppose now that there is a fiscal authority that levies flat rate taxes on labor income

\footnotetext{
${ }^{10}$ If the external effect takes the form as specified in Lucas (1988), then the importation of labor into the humancapital-rich country will lower its average productivity of labor and the wage profile of its workers. The country may therefore impose restrictions on labor importation unless sufficient compensation is obtained from the labor-exporting country. In the absence of such restrictions, the level convergence result stated in our proposition will carry over.
} 
$\left(\tau_{\mathrm{wt}}\right)$ and capital income $\left(\tau_{\mathrm{rt}}\right)$. We allow for tax-deductibility of depreciation expenses for physical capital $\left(\tau_{\mathrm{rt}} \delta_{\mathrm{k}} \mathrm{K}_{\mathrm{t}}\right)$ and, possibly, human capital $\left(\phi \tau_{\mathrm{wt}} \delta_{\mathrm{h}} \mathrm{N}_{\mathrm{t}} \mathrm{h}_{\mathfrak{t}}\right.$, with $\phi=1$ if deductible and $\phi=0$ otherwise) as well. If depreciation of human capital is tax-deductible, and if income taxation is comprehensive and uniform so that the tax rates on labor and capital incomes are equal, the tax treatment of the two forms of capital becomes symmetric. As usual, in order to focus on the distortionary effects of taxation, we assume that the tax proceeds are rebated in a lump-sum fashion to the households. The consumer budget constraint is rewritten as

$$
\begin{aligned}
& N_{t} C_{t}+K_{t+1}-\left(1-\delta_{k}\right) K_{t}-B_{t+1}+\left(1+r_{t}\right) B_{t}-T_{t} \\
= & \Omega_{w t} w_{t} n_{t} N_{t} h_{t}+\phi \tau_{w t} \delta_{h} w_{t} N_{t} h_{t}+\Omega_{r t} r_{k t} K_{t}+\tau_{r t} \delta_{k} K_{t}
\end{aligned}
$$

where $T_{t}$ is the lump-sum rebate, and the tax wedges are defined as $\Omega_{\mathrm{rt}}=1-\tau_{\mathrm{rt}}$ and $\Omega_{\mathrm{wt}}=$ $1-\tau_{w t}$. The optimization problem facing the household is to choose $\left\{c_{t}, e_{t}, n_{t}, K_{t+1}, N_{t+1}, h_{t+1}, B_{t+1}\right\}_{t=0}^{\infty}$ to maximize utility (1) subject to the laws of motion (2) and (3) and the budget constraint (5), given $\left\{w_{t}, r_{t}, \tau_{w t}, \tau_{r t}, T_{t}\right\}_{t=0}^{\infty}$

\section{IV.1 Absence of Labor Mobility}

To illustrate the effect of taxes on steady state growth rates, we simplify by assuming inelastic child-rearing time (i.e., $v_{t}$ constant over time, implying exogenous population growth). In Appendix 2, we derive the following steady state equation in the time allocated to education (e). 


$$
\begin{gathered}
1=\beta\left(1+g_{h}\right)^{(1-\sigma) \zeta\left(1+g_{N}\right)}\left\{1+\gamma\left(\frac{1-n-e}{e}\right)\left(\frac{g_{h}+\delta_{h}}{1+g_{h}}\right)\left[1+\phi \delta_{h}\left(\frac{\tau_{w}}{\Omega_{w}}\right)\left(\frac{1}{1-n-e}\right)\right]\right\}, \\
\text { where } g_{h}=B e^{\gamma-\delta_{h} .}
\end{gathered}
$$

Direct inspection of equation (6) reveals that the intertemporal (capital) tax wedge $\left(\Omega_{\mathrm{r}}\right)$ has no effect on the allocation of time between work and education, hence growth rates, in the steady state. The source of this neutrality lies in the fact that, in our model, there are no other time-consuming activities (such as leisure) and physical capital is not required for the production of human capital.

In the absence of depreciation allowance for human capital $(\phi=0)$, the intratemporal (labor) tax wedge $\left(\Omega_{w}\right)$ will have no effect on long run time allocation (hence, growth rate) either. This can be understood from Boskin's (1975) argument that increase in the constant tax rate on labor income along the balanced growth path will reduce both the returns (in terms of future wage earnings) and costs (in terms of forgone earnings) of investment in human capital equally at the margin. ${ }^{11}$ When depreciation of human capital is tax-deductible $(\phi=1)$, however, the reduction in returns in terms of future wage earnings due to the wage tax are exactly offset by this allowance. Thus, since only the costs in terms of income forgone are reduced, the labor income tax is no longer neutral.

In reality, tax-deductibility of depreciation of human capital does not exist in the exact form as modelled here, but can be viewed as mimicking the effects of two major common

\footnotetext{
${ }^{11}$ This argument applies to substitution effect between education and work. The potential income effect of taxes is absent in this case due to the homotheticity of preferences.
} 
provisions of taxation: tax progressivity and subsidized health care. ${ }^{12}$ This is proxied by $0<$ $\phi<1$ in our model. On the other hand, our simplified setup has abstracted from modelling other time-consuming activities such as leisure or child-rearing (which drives endogenous population growth), and the use of physical capital as an input in the production of human capital. Adding these features to our model will strengthen the effects of the labor income tax on the growth rate of human capital (and population) and introduce a channel through which the capital income tax may affect the growth rate as well.

In our present model, countries with similar preferences and technology but different labor income tax rates will have different long run growth rates. Differences in capital income tax rates, however, will not lead to divergence in growth rates.

\section{IV.2 Presence of Labor Mobility}

In order to consider the effects of the interaction between labor mobility and international taxation policies on convergence across countries, we need to introduce some additional notations. We shall use $\tau_{\mathrm{wDt}}$ to denote the tax rate on the domestic-source labor income of residents of the home country, $\tau_{\mathrm{wNt}}$ the tax rate on the labor income earned by non-residents in the home country, and $\tau_{\mathrm{WAt}}$ the tax rate on the foreign-source capital income in addition to the taxes paid by the residents of the home country to the foreign government (and similarly for the rest of the world). The mnemonics are such that 'D' stands for domestic-source, 'A' for additional, and ' $\mathrm{N}$ ' for non-residents.

\footnotetext{
${ }^{12}$ The progressivity of income tax implies that the tax rate which could have been applied to forgone income is smaller than the tax rate which is actually applied to the increase in labor earnings due to human capital investment. Subsidized health care in the form of tax-deductibility of medical expenses is equivalent to the depreciation allowance for human capital associated with health.
} 
Under perfect labor mobility, the absence of arbitrage opportunities ensures the equalization of after-tax marginal products of labor (MPHs or wage rates) for any worker who can choose to work in either country. In particular, $\left(1-\tau_{\mathrm{wDt}}\right) \mathrm{MPH}_{\mathrm{t}}=$ $\left(1-\tau_{\mathrm{WAt}}-\tau_{\mathrm{WNt}}^{*}\right) \mathrm{MPH}_{\mathrm{t}}^{*}$. This arbitrage-based relation is used in Appendix 3 to derive the following fundamental relative growth equation: ${ }^{13}$

$$
\begin{gathered}
\left(\frac{1+g_{y}}{1+g_{y}^{*}}\right)^{(\xi-1)+o \zeta}=\frac{1+\left(1-\tau_{x D}\right)\left(r_{k}-\delta_{k}\right)}{1+\left(1-\tau_{r D}^{*}\right)\left(\Gamma r_{k}-\delta_{k}\right)}, \\
\text { where } \Gamma=\Lambda\left(\frac{\bar{h}^{*}}{\bar{h}}\right)^{\frac{\epsilon}{\alpha}} \text { and } \Lambda=\left(\frac{1-\tau_{w A}-\tau_{w N}^{*}}{1-\tau_{w D}}\right)^{\frac{\alpha}{1-\alpha}} .
\end{gathered}
$$

In Section III.3, we saw how labor mobility combined with knowledge spillovers could bring about convergence in income levels in the absence of tax differences. Equation (7) reveals, however, that in the presence of tax differences, growth rates and levels are not in general equalized across countries. We can therefore view cross-country tax asymmetry as both a growth-diverging and level-diverging force.

To see more specifically which country will achieve higher level of income, we consider the following cases. Suppose there is preference bias towards child quantity in all countries (i.e., $\xi>1-\sigma \zeta) .{ }^{14}$ Consider first the case that either the residence principle is applied to labor taxation or that labor income taxes are source-based and symmetric across countries (so that $\Lambda=1$ ). If the home country taxes capital more heavily than the foreign country (i.e., $\tau_{\mathrm{rD}}$ $>\tau_{\mathrm{rD}}^{*}$ ), then we can observe from equation (7) that $\mathrm{g}_{\mathrm{y}}<\mathrm{g}_{\mathrm{y}}^{*}$ and $\overline{\mathrm{h}}<\overline{\mathrm{h}}^{*}$. Thus, regardless

\footnotetext{
${ }^{13}$ Note that $\tau_{\mathrm{WD}}=\tau_{\mathrm{WA}}$ and $\tau_{\mathrm{WN}}=0$ (implying $\Lambda=1$ ) under the residence principle of wage taxation, and $\tau_{\mathrm{wD}}$ $=\tau_{\mathrm{wN}}$ and $\tau_{\mathrm{wA}}=0$ (implying $\Lambda \sum 1$ as $\tau_{\mathrm{wD}} \sum_{\mathrm{wD}}^{*}$ ) under the source principle.

14 In Razin and Yuen (1996), we show in the context of a calibrated model for the G-7 countries that $\xi>1-\sigma$, which implies this condition (given $\zeta>1$ ).
} 
of the initial income level differentials, the (detrended) steady state income level of home country will be lower than that of the foreign country. The converse will be true if $\tau_{\mathrm{rD}}<\tau_{\mathrm{rD}}^{*}$. Consider next the case where $\tau_{\mathrm{rD}}=\tau_{\mathrm{rD}}^{*}$ and labor income taxes are source-based and asymmetric across countries. In particular, suppose that home country levies higher tax rates on labor than the foreign country (i.e., $\tau_{\mathrm{wD}}>\tau_{\mathrm{wD}}^{*}$ ). Then inspection of equation (7) reveals that $\mathrm{g}_{\mathrm{y}}<\mathrm{g}_{\mathrm{y}}^{*}$ and $\overline{\mathrm{h}}<\overline{\mathrm{h}}^{*}$, so that the home country's (detrended) steady state income level will be lower than that of the foreign country, regardless of initial conditions. The converse holds if $\tau_{\mathrm{wD}}<\tau_{\mathrm{wD}}^{*}$. Note that, in all these cases, we may have the possibility that a country that starts from a lower income level may overtake an initially higher income country in the long run due to tax advantages.

A full-fledged tax harmonization under which tax rates on income from capital and income from labor respectively are unified across countries will eliminate all fundamental sources of heterogeneity among countries in the steady state (given identical preferences and technology). Thus, while the arbitrage-based relation continues to hold, non-zero labor flows are not necessary to support this relation and the actual labor flows will cease to exist. Equation (6) in the no labor mobility case will again hold. This, combined with the relative growth equation (7), implies complete convergence in levels and growth rates.

\section{Growth Policies with Knowledge Spillovers}

The spillover effect has been shown to be an important driving force behind income equalization across countries achieved through labor mobility. In the presence of distortionary taxes, the equality objective requires harmonization of income tax rates. However, the existence 
of knowledge spillovers implies that market forces and uncoordinated government actions may fail to direct the world economy to an efficient growth path. This section provides an analysis of policies that will internalize this human capital externality within and across countries to achieve efficient growth. To simplify, we assume throughout this section that population growth rates are exogenously given and equal across countries and that $\delta_{\mathrm{h}}=1 .{ }^{15}$ We also abstract from distortionary income taxes in order to focus on the efficiency issue.

\section{V.1 Absence of Labor Mobility}

To consider efficient growth, we invoke the metaphoric social planner, who maximizes dynastic utility (1) subject to the resource constraint (4) and the law of motion of human capital (2). Unlike the private agent who ignores his/her own potential contribution to the uppermost skill level in the economy, the planner internalizes the human capital externality by equating the skill level of the smartest guy $(\overrightarrow{\mathrm{h}})$ to the representative agent's skill level $(\mathrm{h})$ in solving the social planning problem. ${ }^{16}$

The efficient path can then be decentralized as an equilibrium growth path by a proper subsidy scheme of the Pigouvian kind. The subsidy we consider is targeted at the fraction of time allocated to education, and is financed through lump-sum taxes. Accordingly, we attach $s_{t} e_{t}-T_{t}$ as an extra source of income to the right hand side of the consumer's budget constraint (5). Re-deriving the equilibrium conditions under this growth policy and comparing them with

\footnotetext{
${ }^{15}$ Since our analysis here does not focus on steady states, we do not need to assume endogenous population growth.

${ }^{16}$ The first order condition for $h_{\mathfrak{t}+1}$ will include an extra term which captures the external effect. In particular, $\mu_{h_{t}}=\beta\left\{\mu_{h_{t+1}}\left[B e_{t+1}^{\gamma}+\left(1-\delta_{h}\right)\right]+\mu_{t+1}(\alpha+\epsilon) A K_{t+1}^{1-\alpha}\left(N_{t+1} n_{t+1}\right)^{\alpha} h_{t+1}^{\alpha+\epsilon-1}\right\}$.
} 
the optimality conditions of the social planner implies that the optimal subsidy to education is given by

$$
s_{t} e_{t}=\epsilon \gamma \sum_{j=t+1}^{\infty}\left(d_{j} Y_{j}\right)
$$

where $d_{j}$ is the present value factor based on market rates of interest (equal to the intertemporal marginal rate of substitution between time-j consumption time-t consumption). In words, the optimal subsidy is equal to the product of the external effect and the present discounted value of additional future GDPs due to human capital investment.

\section{V.2 Presence of Labor Mobility}

Following similar procedures, the uncoordinated Cournot-Nash world equilibrium yields the same optimal subsidy rate for the labor-exporting (home) country and the labor-importing (foreign) country. Since the importation of lower-quality labor does not drag down the average productivity of workers, international coordination of growth policy is not required for complete internalization of inter-country spillovers and global efficiency. ${ }^{17}$

\section{Summary}

Evidently, explicit barriers to labor mobility do not exist within Europe, but significant implicit

${ }^{17}$ Under the Lucas-type externality, however, the optimal subsidy for the labor-importing (foreign) country becomes

$$
s_{t}^{*} e_{t}^{*}=\theta^{*} \in \gamma \sum_{j=t+1}^{\infty}\left(d_{j}^{*} Y_{j}^{*}\right)
$$

where $\theta^{*}$ is the proportion of foreign country population in the world population. Thus, from the world perspective, the foreign country will under-subsidize education. Since the labor-importing country cannot prevent the spillover of knowledge to the labor-exporting country, it will not attempt to fully internalize the human capital externality globally when designing its optimal education subsidy. As a result, the world as a whole fails to achieve efficient growth. Under such circumstances, a coordinated growth policy is required for complete internalization of inter-country spillovers and global efficiency. 
restrictions on labor flows are prevalent. More specifically, privatizing pension schemes and moving towards a portable social security and unemployment benefits schemes will facilitate labor mobility.

Despite the important role we establish for the integration of labor markets across Europe as an income-equalizing device, several questions remain as to whether alternative channels exist for income level convergence as substitutes for labor mobility.

(a) Can free trade in commodities be a substitute for labor mobility?

In the presence of knowledge spillovers, free trade in goods can only accomplish relative factor price equalization. Wages, hence human capital and per capita income levels will not be equalized across countries.

(b) Can interstate income transfers across Europe be a substitute for labor mobility?

Since the gaps in initial skill levels among the European states cannot be closed by such transfers, income level convergence will require increasingly more sizable transfers over time. In other words, unless the EC budget is unlimited, such redistributive policy is not sustainable and will not be able to close the interstate income gaps in the long run. ${ }^{18}$

Future research may discover alternative mechanisms for income level convergence without necessarily resorting to labor mobility.

${ }^{18}$ As Bayoumi and Masson (1995) show empirically, "the small size of the EC budget and the wide differences in income levels across EC countries means that the potential for redistribution across EC states is small." 


\section{Appendix 1: Proof of the Labor-Mobility-Level Convergence Proposition}

For any two countries A and B with labor flowing from B to A, the proposition states in more technical terms that: Along the steady state growth path with nonzero labor flows and $\tilde{\epsilon}>0, g_{h}^{A}=g_{h}^{B}$ and $h^{A}=$
$h^{B}$,

Proof: Along the global steady state growth path, $g_{K}^{i}=g_{Y}^{i}(i=A, B)$ and the ratios of the cross-border labor income $w^{A}\left(1-n^{B}\right) N^{B} h^{B}$ to both GDP $P^{A}$ and $G D P^{B}$ must be constant. Given the Cobb-Douglas production function, these balanced growth conditions imply that: $\left(1+g_{N}^{A}\right)\left(1+{ }_{h}^{A}\right)=\left(1+g_{N}^{B}\right)\left(1+g_{h}^{B}\right)$, and

$$
\frac{1+g_{Y}^{A}}{1+g_{Y}^{B}}=\left(\frac{1+g_{h}^{B}}{1+g_{\bar{h}}^{A}}\right)^{\frac{\tilde{\epsilon}}{\epsilon}} .
$$

From the Cobb-Douglas function and the equality $\mathrm{g}_{\mathrm{K}}^{\mathrm{i}}=\mathrm{g}_{\mathrm{Y}}^{\mathrm{i}}(\mathrm{i}=\mathrm{A}, \mathrm{B})$, we also have

$$
\frac{1+g_{Y}^{A}}{1+g_{Y}^{B}}=\left(\frac{1+g_{\bar{h}}^{A}}{1+g_{h}^{B}}\right)^{\frac{\epsilon}{1-\epsilon}} \text {. }
$$

Combining the two conditions above, we have $\mathrm{g}_{\mathrm{h}}^{\mathrm{A}}=\mathrm{g}_{\mathrm{h}}^{\mathrm{B}}$. Along the equilibrium balanced path, the fundamental growth equation a la Rebelo (1992) can be expressed as:

$$
\left(\frac{1+g_{h}^{A}}{1+g_{h}^{B}}\right)^{(\xi-1)+o \zeta}=\frac{r^{A}}{r^{B}}=\frac{z^{B}}{z^{A}} \text { where } z^{A}=\frac{K^{A}}{N^{A} h^{A}+N^{B} h^{B}\left(1-n^{B}\right)} \&
$$

where, as in Section III, $\xi$ reflects the consumer's preference for the quantity of children, and $\sigma$ reflects the consumer's preference for the quality of children. The second equality follows from $\mathrm{r}^{\mathrm{i}}=\epsilon \mathrm{w}^{\mathrm{i}} /(1-\epsilon) \mathrm{z}^{\mathrm{i}}$ and the wage equality condition: $\mathrm{w}^{\mathrm{A}}=\mathrm{w}^{\mathrm{B}}$.

But $g_{h}^{A}=g$, implying equality of interest rates and hence capital-effective-labor ratios. Substituting back into the wage equality condition, $z^{A}=z^{B}$ implies that $h^{A}=h^{B}$. This proves the proposition. 


\section{Appendix 2: Derivation of the Tax-Growth Relation in the Closed Economy}

In this appendix, we derive equation (6) in the text. The consumer's first order conditions (C) with respect to $c_{t}, e_{t}, K_{t+1}$, and $h_{t+1}$ are given by:

$$
\begin{gathered}
C_{t}^{-\sigma}=\mu_{t} \\
\mu_{h_{t}} \gamma B e_{t}^{\gamma-1}=\mu_{t} \Omega_{w t} w_{t} N_{t} \\
\mu_{t}=\beta \mu_{t+1}\left[1+\Omega_{r_{t+1}}\left(r_{t+1}-\delta_{k}\right)\right] \\
\mu_{h_{t}}=\beta\left\{\mu_{h_{t+1}}\left[B e_{t+1}^{\gamma}+\left(1-\delta_{h}\right)\right]+\mu_{t+1} w_{t+1} N_{t+1}\left[\Omega_{w_{t+1}}\left(1-e_{t+1}\right)+\phi \tau_{w_{t+1}} \delta_{h}\right\} .\right.
\end{gathered}
$$

(C4)

The Lagrange multipliers ( $\mu$ for 'mu'ltipliers) at time $t$ associated with the consumer budget constraint and the law of motion of human capital are denoted by $\mu_{t}$, and $\mu_{\text {ht }}$ respectively. Assuming that the capital income tax rate $\tau_{\mathrm{rt}}$ applies uniformly to both financial and physical capital, the arbitrage condition implies that $r_{t}=r_{k t}-\delta_{k}$. The firm's first order conditions (F) are

$$
\begin{gathered}
w_{t}=(1-\epsilon)\left(\frac{Y_{t}}{H_{t}}\right), \text { and } \\
r_{t}=\epsilon A\left(\frac{Y_{t}}{K_{t}}\right) .
\end{gathered}
$$

The equilibrium conditions in the labor and capital markets $(E)$ are

$$
\begin{gathered}
N_{t} h_{\mathrm{t}}=H_{t}^{d}, \text { and } \\
K_{t}=K_{t}^{d} .
\end{gathered}
$$

Substituting (2) and (F1) into (C2), we get,

$$
\frac{\gamma \mu_{h_{t}}\left[h_{t+1} / h_{t}-\left(1-\delta_{h}\right)\right]}{e_{t}}=\frac{\alpha \mu_{t} \Omega_{w_{t}} Y_{t}}{1-e_{t}} \text {. }
$$

Along the balanced growth path, time allocations and tax rates are constant, i.e., $e_{t}=e_{t+1}$, 
$\Omega_{\mathrm{t}}=\Omega_{\mathrm{t}+1}, \Omega_{\mathrm{wt}}=\Omega_{\mathrm{wt}+1}$, and $\Omega_{\mathrm{rt}}=\Omega_{\mathrm{rt}+1}$, and human capital and consumption will grow at the same constant rate $g_{h}$ and output at the rate $\left(1+g_{N}\right)\left(1+g_{h}\right)-1$ respectively, so that (C1) and (A2.1) imply that

$$
\frac{\mu_{h_{t+1}}}{\mu_{h_{t}}}=\frac{\mu_{t+1} Y_{t+1}}{\mu_{t} Y_{t}}=\left(1+g_{N}\right)\left(1+g_{h}\right)(1-o) \zeta
$$

Multiplying (C4) throughout by $h_{t+1}$ and dividing the resulting expression by $\beta \mu_{h t+1} h_{t+2}$, we get

$$
\begin{gathered}
\frac{\mu_{h_{t}} h_{t+1}}{\beta \mu_{h_{t+1}} h_{t+2}}=1+\left(\frac{\mu_{t+1} Y_{t+1}}{\mu_{h_{t+1}} h_{t+2}}\right) \alpha\left[\Omega_{w}+\phi \delta_{h} \tau_{w}\left(\frac{1}{1-e}\right)\right], \\
\text { where } \frac{\mu_{t+1} Y_{t+1}}{\mu_{h_{t+1}} h_{t+2}}=\left(\frac{\gamma}{\alpha \Omega_{w}}\right)\left(\frac{1-e}{e}\right)\left(\frac{g_{h}+\delta_{h}}{1+g_{h}}\right) .
\end{gathered}
$$

Combined with (A2.2), this yields equation (6) in the text. 


\section{Appendix 3: Derivation of the Relative Growth Equation}

Rates of growth of per capita consumption and population $\left(g_{c}\right.$ and $\left.g_{N}\right)$ are related to the rates of return on physical capital through the intertemporal conditions:

$$
\begin{gathered}
\left(1+g_{N}\right)^{1-\xi}\left(1+g_{c}\right)^{\circ \zeta}=1+\left(1-\tau_{r D}\right)\left(r_{k}-\delta_{k}\right), \text { and } \\
\left(1+g_{N}^{*}\right)^{1-\xi}\left(1+g_{c}^{*}\right)^{\sigma \zeta}=1+\left(1-\tau_{r D}^{*}\right)\left(r_{k}^{*}-\delta_{k}\right) .
\end{gathered}
$$

Along the steady state growth path, $g_{c}=g_{y}$ and $g_{c}^{*}=g_{y}^{*}$ and, as we have shown in Section III. $2,\left(1+g_{N}\right) /\left(1+g_{N}^{*}\right)=\left(1+g_{y}^{*}\right) /\left(1+g_{y}\right)$. Substituting these conditions into the above equations, and dividing one equation by the other, we get

$$
\left(\frac{1+g_{y}}{1+g_{y}^{*}}\right)^{(\xi-1)+o \zeta}=\frac{1+\left(1-\tau_{r D}\right)\left(I_{k}-\delta_{k}\right)}{1+\left(1-\tau_{r D}^{*}\right)\left(I_{k}^{*}-\delta_{k}\right)} .
$$

The arbitrage-based relation, $\left(1-\tau_{\mathrm{wDt}}\right) \mathrm{MPH}_{\mathrm{t}}=\left(1-\tau_{\mathrm{wAt}}-\tau_{\mathrm{wNt}}^{*}\right) \mathrm{MPH}_{\mathrm{t}}^{*}$, implies that MPK $_{\mathrm{t}}^{*}=\Gamma_{\mathrm{t}} \mathrm{MPK}_{\mathrm{t}}$, where $\Gamma_{\mathrm{t}}$ is as defined in the text. Substituting this into the above yields equation (7) in the text. 


\section{References}

Atkeson, Andrew, and Tamim Bayoumi, "Do Private Capital Markets Insure Regional Risk? Evidence from the United States and Europe," Open Economies Review 4 (1993): 303-24.

Bayoumi, Tamim, and Paul R. Masson, "Fiscal Flows in the United States and Canada: Lessons for Monetary Union in Europe," European Economic Review 39 (1995): 253-74.

Becker, Gary S. and Robert J. Barro, "A Reformulation of the Economic Theory of Fetility," Quarterly Journal of Economics 103 (1988), 1-25.

Blanchard, Olivier, and Juan F. Jimeno, "Structural Unemployment: Spain versus Portugal," American Economic Review Papers and Proceedings 85 (1995): 212-18.

Eichengreen, Barry, "One Money for Europe? Lessons from the US Currency Union," Economic Policy: A European Forum 10 (1990): 117-66.

Frenkel, Jacob and Assaf Razin, with Chi-Wa Yuen, Fiscal Policies and the World Economy: New Edition. Cambridge: MIT Press (1996).

Lucas, Robert E., Jr., "On the Mechanics of Economic Development," Journal of Monetary Economics 22 (1988), 3-42.

, "Why Doesn't Capital Flow from Rich to Poor Countries?" American Economic Review Papers and Proceedings 80 (1990), 92-6.

Mendoza, Enrique G., Assaf Razin, and Linda L. Tesar, "Effective Tax Rates in Macroeconomics: Cross Country Estimates of Tax Rates on Factor Incomes and Consumption," Journal of Monetary Economics 34 (1994): 297-323.

OECD, Employment Outlook, 1990, Table 3.3.

Razin, Assaf, "Investment in Human Capital and Economic Growth," Metroeconomica 24 (1972), 101-117.

Razin, Assaf and Uri Ben-Zion, "An Intergenerational Model of Population Growth," American Economic Review 69 (1975), 923-933.

Razin, Assaf and Chi-Wa Yuen, "Capital Income Taxation and Long Term Growth: New Perspectives," Journal of Public Economics, 1996, forthcoming.

Rebelo, Sergio T., "Long Run Policy Analysis and Long Run Growth," Journal of Political Economy 99 (1991): 500-21.

"Growth in Open Economies," Carnegie-Rochester Conference Series on Public Policy 36 (1992), 5-46.

Summers, Robert, and Alan Heston, "A New Set of International Comparisons of Real Product and Price Levels: Estimates for 130 Countries, 1950-1985, "Review of Income and Wealth 34 (1988), 1-25.

Uzawa, Hirofumi, " Optimum Technical Change in an Aggregate Model of Economic Growth," International Economic Review 6 (1965), 18-31. 


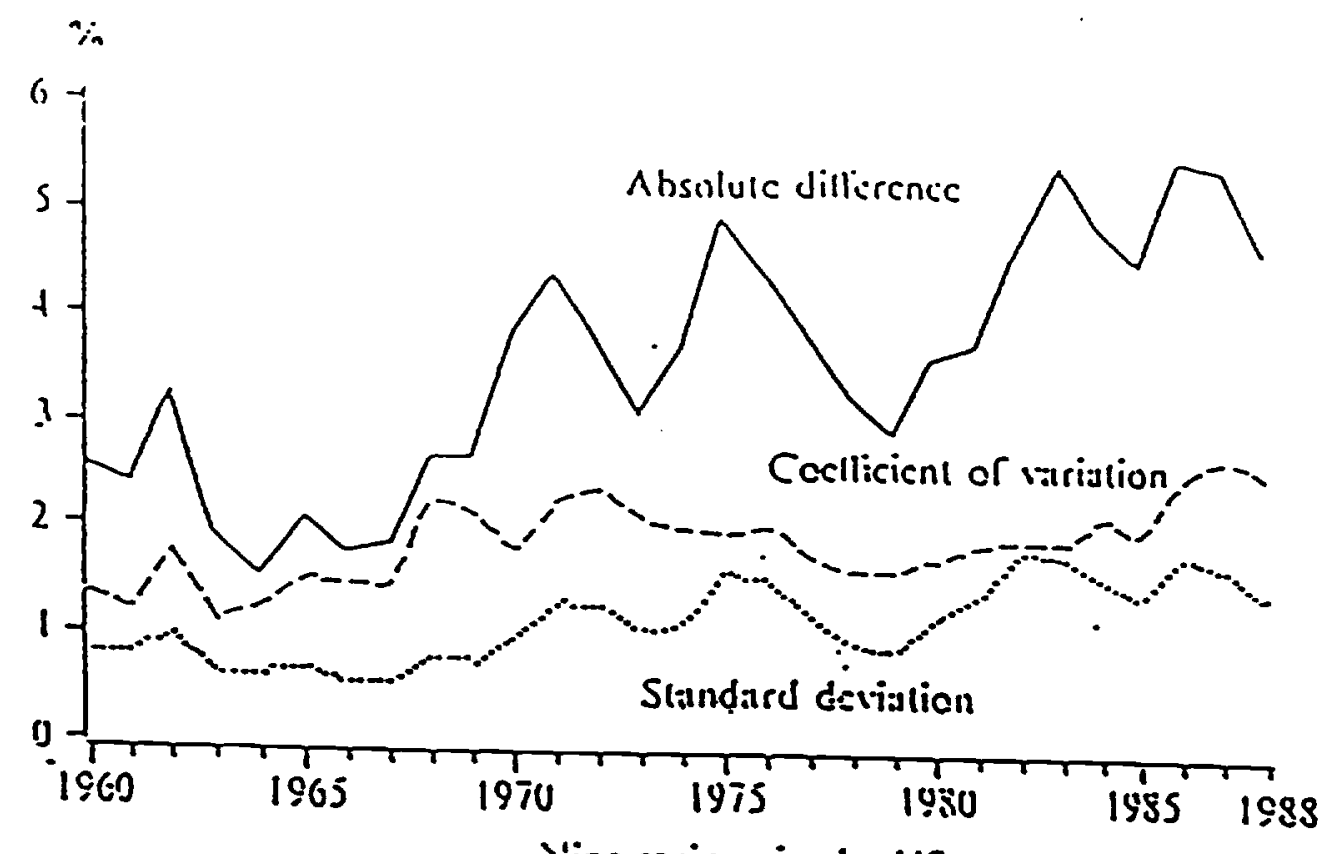

Nine regions in the US

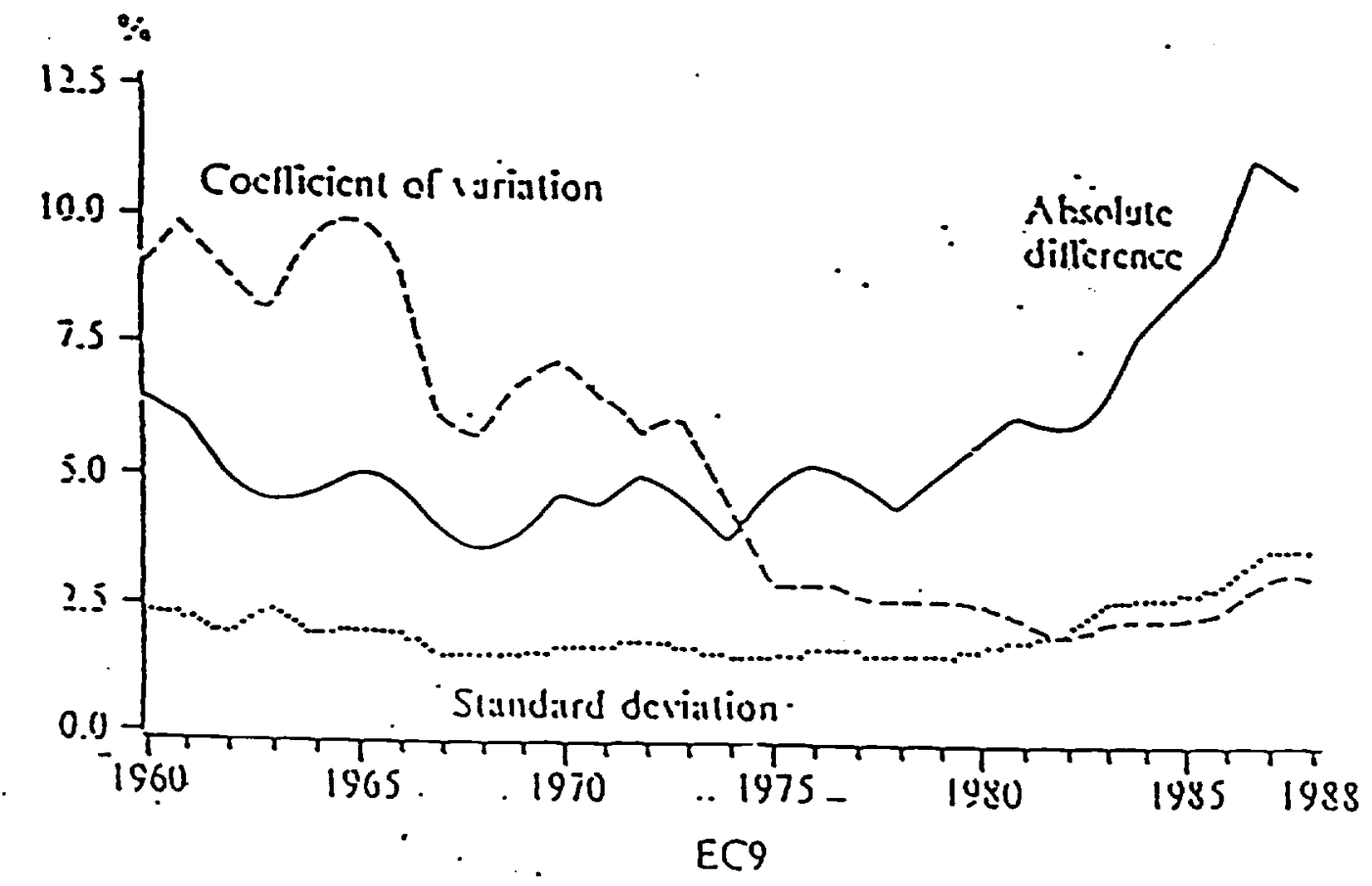

Figure 1 . Dispersion of unemployment rates Source: Eichengreen (1990) 


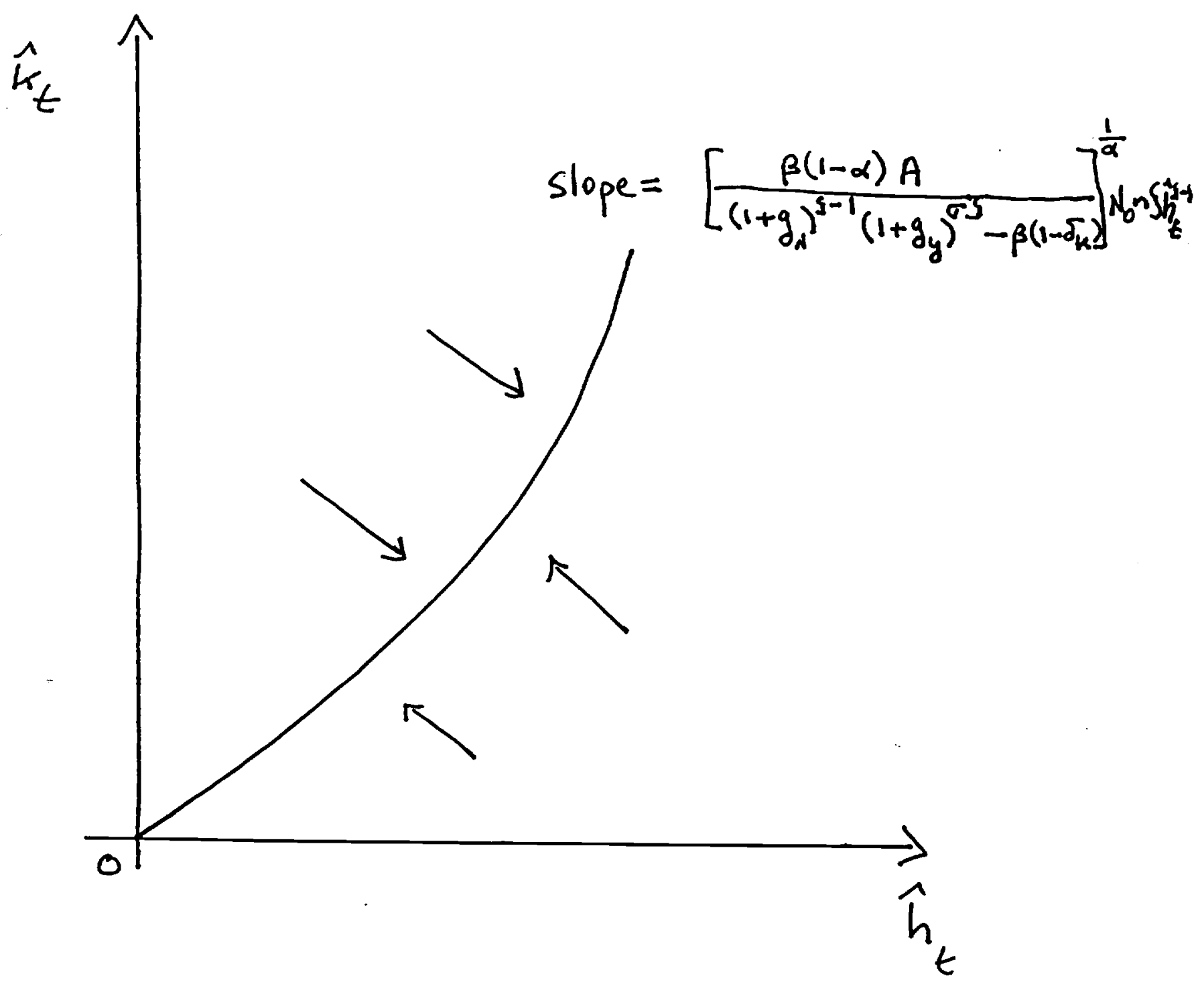

Figure 2: Convergence in the Presence of Human Capital Externality 